Max-Planck-Institut für demografische Forschung

Max Planck Institute for Demographic Research

Doberaner Strasse 114 - D-18057 Rostock · GERMANY

Tel +49 (0) 3812081 - 0; Fax +49 (0) 3812081 - 202;

http://www.demogr.mpg.de

MPIDR WORKING PAPER WP 2001-025

AUGUST 2001 (REVISED NOVEMBER 2001)

\title{
Spatial profiles in the analysis of event histories: An application to first sexual intercourse in Italy
}

Francesco C. Billari (billari@demogr.mpg.de)

Riccardo Borgoni (borgoni@demogr.mpg.de)

(C) Copyright is held by the authors.

Working papers of the Max Planck Institute for Demographic Research receive only limited review. Views or opinions expressed in working papers are attributable to the authors and do not necessarily reflect those of the Institute. 


\title{
Spatial pro. les in the analysis of event histories
}

\section{An application to ..r.st sexual intercourse in Italy}

\author{
Francesco C. Billari and Riccardo Borgoni \\ Max Planck Institute for Demographic Research \\ Doberaner Str. 114 \\ D-18057 Rostock, Germany. \\ E-mail: \{bi I I ari , borgoni \}@lenogr. mpg. de
}

November 16, 2001

\begin{abstract}
A bstract
Theai m of this paper is mainly a methodological one. We used individual-level retrospective data from the Italian Fertility and Family survey, based on the information provided by respondents. Linking individual-level data with geographical characteristics of the community, we .r.stly used non-parametric methods, and in particular the bi-dimensional LOESS (Locally weighted regression) method, to build smoothed maps of the transition to ..rst sexual intercourse Secondly, we used a discrete-time multilevd event-history mode (with logit speci..cation), allowing for the presence of unobserved heterogeneity at themunicipality level. We used 'latitude', 'Iongitude', and dimension of the municipality as aggregatelevel explanatory variables in the mode. Thus, we could build spatial pro. les and a map, using predicted values for the logodds-ratio, and we could study cohort dynamics too. Our results con. r.m that Italy is a heterogeneous country; when looking at age at the .r.st sexual intercourse, women are more infuenced by their context than men.
\end{abstract}




\section{Introduction}

The study of demographic events has traditionally been based on their empirical investigation over time and space. The central role of time (in particular of individual time expressed by age or other relevant duration variables, together with cohort and period) has been recognized by researchers, who developed classical techniques, such as life tables. The development of more recent techniques that deal with individual-level timeto-event data, (i.e. event history analysis), has led to a specialized set of techniques of statistical demography. On the other hand, spatial aspects have occupied a peripheral position in formal and statistical demography, and even more so does the interaction between space and time

Analyses of demographic phenomena across space, and the representation of such phenomena using maps, have substantially contributed to major research eaorts in demography. The Princeton project (Coale and Watkins, 1986) extensively relied on maps to describethe dynamics of the demographic transition and to support explanatory ideas. As it has been pointed out by Lesthaeghe and Neels (2000) "maps produce good narratives, and these in their turn are valuable for theory formation as well". Thus, spatial analysis has had an important role in the development of key theories that explain demographic behavior. GIS packages, similar to those we exploit in this paper, provide unique features for drawing maps using low levels of geographical aggregation.

During the last twenty years, spatial statistics has developed into a specialized ..eld, and several monographs have been published on this subject (Ripley, 1981; Diggle, 1983; Ripley, 1988; Cressie, 1993). Most studies relate to epidemiology, and their authors make use of aggregatelevel spatial data. The spatial analysis of (bio-)demographic data is another developing ..eld (Sleegers and Goethals, 1993; Bocquet-Appel et al., 1996). One of the key issues in this stream of research is the link between space and time (the latter is de. ned both in terms of societal time and individual time). The same link is discussed in epidemiologically-oriented demographic studies (see for instance Congdon, 2000). For individual-level data, non-parametric or semi-parametric methods have been used (for a review see Diggle (2000) and the bibliographic references listed there). 
The aim of this paper is mainly a methodological one. Using the most widespread set of statistical techniques used in modern demographic research, event history analysis (Courgeau and Lelièvre, 1989; Blossfeld and Rohwer, 1995), we incorporated in our analysis a spatial approach. In event history analysis, the spatial correlation among individuals is sometimes taken into account insofar as space introduces a hierarchical structure to data. This idea is embedded in so-called multilevel models. In these models, correlation is allowed among units in the same area, but independence is assumed among areas. Examples of this approach include Steele et al. (1996) and Barber et al. (2000) for discrete time, and Boldstad and Manda (2001) for continuous time. A spatial, discretetime event history model, that allows also for timevarying eaects, is developed within a full Bayesian framework by Fahrmeir and Lang (2001), who use a uni..ed approach for Bayesian MCMC inference in generalized additive and semi parametric mixed models.

Given the importance of retrospective surveys in demography, we exploit Fertility and Family Survey data. We present an application to age at .r.st sexual intercourse of Italian men and women. For behaviors such as .r.st sexual intercourse, where Italy is a relatively traditional country according to Western standards, though large and relatively stable dixerentials also exist betwen countries (Bozon and Kontula, 1997). Cultural components such as social norms, religiosity, and long-standing family structures play a key role in shaping geographical dixerences in the timing of the .r.st sexual intercourse (see eg. Buzzi, 1998). The latter is a behavior for which the cultural heterogeneity of Italy can emerge from spatial analysis, with the possibility of crossing traditional administrative categorizations being an advantage. A south-north gradient is plausible at least for women, given that southern Italy is a rather traditional part of the country. To give an example, according to Cazzola (1999), north-eastern regions have an estimated odds-ratio of 3.46 over southern regions, regarding to ..r.st sexual intercourse by the age of 19.

The methods we propose also allow for an investigation of the possibility that a spatial dixusion process occurs. We form the hypothesis that new behavior, for instance sexual debut at an earlier age, follows a dixusion process across space. We discuss this point explicitly when we analyze cohort dynamics.

The paper is structured as follows. After a brief description of the data (Section 2), 
we use non-parametric methods to draw maps of Italy based on the timing of the ..rst sexual intercourse (Section 3). In Section 4, we usea multi-level discrete-timeevent history model in order to estimate a spatial pro. le by latitude and longitude. Section 5 outlines a societal time perspective by comparing large groups of cohorts Section 6 concludes the paper and suggests avenues for further research.

\section{Data}

We use individual-level retrospective data from the Italian Fertility and Family survey (De Sandre et al., 1997). A total number of 4,824 females and 1,206 males, were interviewed, representing a cross-section of residents born betwween 1946 and 1975. Among other questions on reproductivehealth, the respondents wereasked about their age at ..r.st sexual intercourse (if they had any). The interviews were conducted between November 1995 and J anuary 1996 and the age at .r.st sexual intercourse was reported in completed years. A range of checks showed that the data quality was very satisfactory (Cazzola, 1999), and the self-reported age at ..rst intercourse has been shown to be a reliable indicator (Dunne et al., 1997). In general, the data showed that ..rst sexual intercourse in I taly takes place at a higher age than in other western European countries. The paper by Cazzola (1999) contains a detailed description of the data and some analyses.

In order to link individual data to the geographical context, we used the information provided by respondents who resided in a municipality for most of their time for the .r.st 15 years of their life. Given that complete residential histories are not available from the survey, this method proved to be the best choice when studying .r.rst sexual intercourse. It has obvious advantages compared to the alternative solution of using as a criterion residence at the time the interview takes place. Of course, we can neither be completely sure that the .r.st sexual intercourse was experienced at the place of residence, nor do we know for sure that it happened after change of residence (if any). We linked the individual-level data with data of the municipality of main residence for ..r.st 15 years of one's life, using geographical coordinates (latitude and longitude) together with dimensional characteristics (population at the 1991 census). 


\section{Maps of Italy: A nonparametric spatial approach}

We .r.st built maps of the transition to ..r.st sexual intercourse, taking a non-parametric approach, which takes explicitly into account the geographical coordinates of the community. Essentially, this involves the application of two-dimensional smoothing techniques to the data of the survey, using a two-step procedure. In the.r.st step, we compute estimates of the quantities of interest at the area level. In the second step, we use nonparametric smoothing techniques to build a visual representation of the geographical pattern of the process. Thus, the aim of our analysis is not to produce estimates at the level of small areas, but to draw maps that describe-in a consistent way-the dixerences in the timing of the event under study across the whole country.

\subsection{M ethods}

We considered two separate procedures, which provide two dixerent indicators of the timing of ..r.st sexual intercourse. In the .r.st procedure, we showed spatial patterns based on non-parametric estimates of the survival function. This approach is appropriate for the data available to us. For this purpose, and given the size of the sample, we computed aggregate measures. In particular, we computed the median age of the .r.st intercourse for each Italian province (103 values). We then applied the smoothing techniques, by using the central coordinate of the provinceas thelocation for the nonparametric estimates. The estimated values were subsequently extended to each municipality, with the possibility of having dixerent values for each province.

In the second procedure, we built our spatial patterns starting directly from data assigned to thegeographical coordinates of the municipality. For each municipality, for which there is at least one case in the sample, we calculated the frequency of ..rst intercourse below a given age. At this level it is impossible to compute the median survival level. Consequently, frequencies for this indicator potentially ranged from 0 to $100 \%{ }^{1}$. Subsequently, we applied smoothing techniques to obtain an estimated value for every Italian municipality. As for the ages selected, we used the median age (to the closest integer) for

\footnotetext{
${ }^{1}$ The frequency of ..rst intercourse below a given age was used in the analysis by Cazzola (1999).
} 
each sex, that is 18 years for males and 19 years for females.

In both cases we used the smoothing method LOESS (robust LOcally weighted re grESSion) (Cleveland, 1979) ${ }^{2}$. The estimator is based on the q points of the sample that are nearest to the currently estimated observation (with $1 \cdot q \cdot n$ where $n$ is the sample size). A local polynomial of degree $d$ is ..tted using weighted last squares, where the nearest points are the most important ones in the computation of ..tted values. The regression coec cients are estimated in order to minimize the following expression:

$$
{ }_{k=1}^{n} w_{k}\left(x_{i}\right)\left(y_{k} i{ }_{0}{ }_{0}{ }^{-}{ }_{1} x_{k}+\ldots: i{ }_{d} x_{k}^{d}\right)^{2}
$$

where $w_{k}(x)$ is derived from the suitable kernel function $w(x)$, which weights observations according to their distance from the current point. This estimator is built by a iterative procedure that repeatedly down-weigthts outliers from the curve estimated in the previous step. In our application, we opted for a second order polynomial function. We used the so called 'tri-weight'function de.ned as

$$
w(x)=\left(1_{i} j x^{3}\right)^{3} \quad j x j<1 \quad w(x)=0 \quad j x j \cdot 1:
$$

If $\hat{\wedge}\left(x_{i}\right)$ is the vector of estimated parameters the estimated value for $y_{i}$ is $\hat{y}_{i}=$ $P_{r=1}^{d} \hat{r}\left(x_{i}\right) x_{i}^{r}$.

The generalization to higher dimension surfaces is described in Cleveland and Devlin (1988). In this case, the method gives a multivariate surface in $p+1$ dimensions if $p$ regressors are used. In a multivariate context a p-dimensional neighborhood must be selected in the predictor space. The selected points are the q nearest points to the $p$ variate point $\left(x_{i}\right)$, relative to the $i$-th observation currently estimated. Once again, each

\footnotetext{
${ }^{2}$ LOESS was initially introduced in order to produce a smoother version of scatter plots, i.e. to accom-

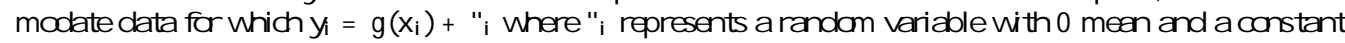
scale, and $g(:)$ represents a smooth function.
} 
point is weighted according to its distance $\left.1 / 2 x_{i} ; x_{k}\right)$ from the current observation by the weight function of the previous type. The metric used here is the usual Euclidean norm. In this case also, the weights are obtained as $\left.w_{k}\left(x_{i}\right)=w\left(1 / k x_{i} ; x_{k}\right)\right)=h_{i}$ where $h_{i}$ is the distance from the $p$-variate point $x_{i}$ from its $q$-th nearest point ${ }^{3}$.

\subsection{Results}

The maps that result from our analysis are shown in Figures 2 and $1^{4}$. For females, one can perceive a spatial trend from south-east to north-west-for both indicators (Figure 2(A) and Figure 1-(A)), with a reversal of the trend in the far north-west. In case of males, the spatial trend appears to be much less evident. Here we observed a more uniform distribution of early intercourse (or, of the lower median age) across the country.

In general, local features play a more important role for males than for females. In case of females, thetraditional south-north gradient appears to be relevant. These results arein line with the expectations presented in the existing literature on this subject. Nevertheless, we shall keep in mind that because of the smaller sample size, the analysis for males suxers from a larger variability factor than the one for females.

\section{A parametric discrete-time event history spatial approach}

\subsection{Methods}

\footnotetext{
${ }^{3}$ In our analysis, we used the LOESS algorithms implemented in S-Plus 2000 (Venables and Ripley, 2000). A feature of the algorithm is that predictions from LOESS are con. ned to the range of the data, both on the $x$ and the $y$ axis. We imputed out-of-range values with a spatial trend computed with a Generalized Additive Model (GAM). GAM is a type of nonparametric model widely used in the statistical literature (Hastie and Tibshirani, 1990). GAM is a generalization of the Generalized Linear Model; the linear predictor is replaced by an additive predictor. In the case of $p$ explanatory variables, a GAM model can be de.ned as $g\left({ }^{1}\right)={ }^{\circledR}+{ }_{i=1} f_{i}(x)$; where the response $Y$ is assumed to belong to the exponential family, ${ }^{1}=E(Y)$ and $g(x)$ is a regular function called link function.

${ }^{4}$ In order to build maps at a municipality level for this and subsequent sections, we use the ArcView GIS software package [?].
} 
In order to study the spatial pro. le of the hazard of ..rst sexual intercourse, we used a multilevel (variance component) discrete-time event history model-belonging to the family of generalized linear mixed models (see eg. Goldstein, 1995 and Steele et al., 1996). We built a person-year dataset and we linked area-level spatial variable ${ }^{5}$ with the individuallevel geographical data. The area-level we use is the municipality. Individuals who have not yet experienced .r.rst sexual intercourse at the time of interview are right-censored.

Given that the .r.st sexual intercourse is a non-repeatable event, it is not possible to identify a variance component which represents unobserved heterogeneity at the individual level. It is nevertheless possibleto identify such a component at the area level. This means that we can estimate at the area leve the presence of unobserved factors which infuence the timing of the .r.rst sexual intercourse. We use only spatial characteristics (including the size of the area) as area-level covariates, with linear splines for the speci..cation of their pro. l.e. We designed separate models for men and women.

The general formulation of the model we used is the following:

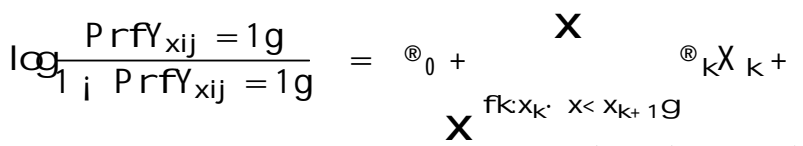

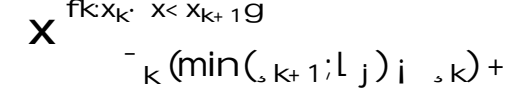

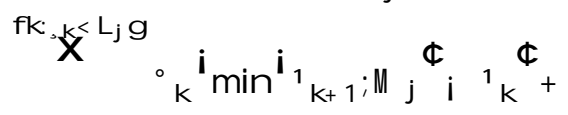

$$
\begin{aligned}
& \mathrm{fk}:{ }^{1} \mathrm{~K}^{<\mathrm{M} g} \\
& \#_{k}\left(\min \left(1 / k+1 ; P_{j}\right) i 1 / k\right)+{ }_{j} ; \\
& \mathrm{f}: \mathrm{l}^{1 / k}<\mathrm{P}_{\mathrm{j}} \mathrm{g}
\end{aligned}
$$

where: $Y_{x i j}$ is the indicator for the ..rst sexual intercourse at age $x$ for the individual $\mathrm{i}$ in the area $\mathrm{j}, \mathbb{\circledR}_{0}$ represents the baseline log-odds-ratio, $X_{k}$ is the indicator for age class $\mathrm{k}=1 ; ;: ;$ I with the lower limit $\mathrm{x}_{\mathrm{k}}$ and the upper limit $\mathrm{x}_{\mathrm{k}+1}\left(\right.$ with $\left.\mathrm{x}_{\mathrm{l}+1}=1\right)$ and $\mathbb{R}_{\mathrm{k}}$ is the log-odds-ratio of the age class $\mathrm{k}$. Moreover we put:

\footnotetext{
${ }^{5}$ Remember that the place of residence is constant across time because we can only use as a reference the .r.st 15 years of an individual.
} 
$f_{k:, k<L_{j} g}^{P}-{ }_{k}\left(\min \left(, k+1 ; L_{j}\right) i, k\right)$ : linear spline for latitude, with knots ..xed at,$k$ (starting from the southern most point in Italy). ${ }_{k}$ represents the slope between,$k$ and ,$k+1$ and $L_{j}$ represents the latitude of area $j$;

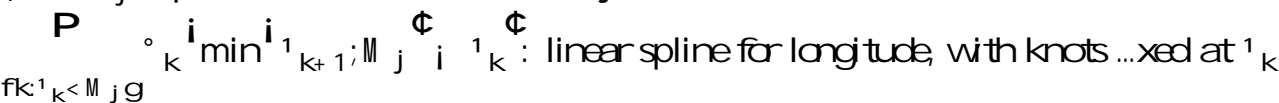
(starting from the western most point in Italy). ${ }_{\mathrm{k}}$ represents the slope between ${ }^{1} \mathrm{k}$ and ${ }^{1}{ }_{k+1}$ and $M_{j}$ represents the longitude of area $j$;

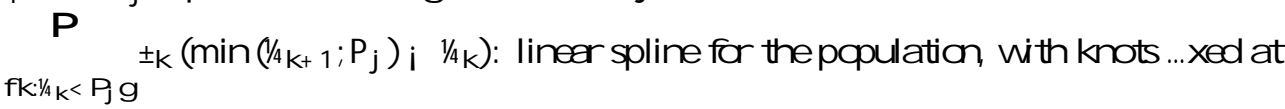
$1 /$. $t_{k}$ represents the slope between $1 / k$ and $1 / k+1$ and $P_{j}$ is the population (in the unit of thousands) of area $\mathrm{j}$ : Finally " $\mathrm{j}$ represents the random residual at the area level distributed as $\mathrm{N}^{\mathrm{i}} 0 ; 3 \mathrm{R}^{\dagger}$ :

We used a full-likelihood speci..cation, which can be implemented by the aML package (Applied Maximum Likelihood) (Lillard and Panis, 2000). Standard errors of theestimates are corrected using a Huber-type procedure (Huber, 1967).

\subsection{Results}

In some of the speci..cations we ..tted a subset of the model just presented. Models 1 and 2 (Tables 1 and 2) were designed, for both males and females, in order to see whether there is a signi..cant component of unobserved heterogeneity at the area level. In other words, we wanted to see whether space (and spacerelated determinats) matters for this behavior. The only other variable which we considered in these models is the age group. As we expected, there clearly was an age trend, with a non-monotonic shape of the hazard reaching its maximum at ages 18 and 19 for males, and 20 and 21 for females. When we focused on unobserved heterogeneity at the area level (estimated in model 2), we gained some interesting insights. For males, the estimated standard deviation of " $\mathrm{j}$ is 0.24 . It is dixerent from zero only at the $5 \%$ signi..cance level, and the likelihood-ratio test rejects the model with unobserved heterogeneity (the $p$-value is 0.16 ). This result is consistent with the ..ndings in the non-parametric part: spatially-related aspects play a less relevant 
role for men than they do for women. In fact, when we analyze model 2 for women, the s.d. is estimated at 0.41 . It is dixerent from zero to with a $p$-value lower than $1 \%$, which is also the case for the likelihood-ratio test. Having obtained our ..r.st results, we proceeded by using models with unobserved heterogeneity at the area model for females only. In what follows, mostly for reasons of comparisons, we continue analyzing males.

\section{TABLES 1, 2 AROUND HERE}

Spatial coordinates are used in models 3, 4 and 5 (theresults are reported in Table 3 for males and Table 4 for females). In model 3, we considered only the south-north gradient, using latitude (which is believed to play the most important role); we then introduced longitude as a further dimension (mode 4). In mode 5, we checked our results, controlling for the size of the place of residence at the 15th birthday.

Theinclusion of latitude and longitude splines improved the model without unobserved heterogeneity at the community level for men (the likelihood-ratio test for mode 4 against mode 1 is 26.28 with 15 d.f. , $p$-value $=0.04$ ). As we expected, this is even more so the case for women (the likelihood-ratio test for mode 4 against model 2 is 224.86 with 15 d.f., pvalue<0.01). These results justify the inclusion of the splines for geographical coordinates for both genders. The results regarding estimates for the parameters of linear splines are not easily interpretable. Nevertheless, they allowed us to produce spatial pro. l.es by plotting them. We also introduced the size of the place of residence as a control variable to draw spatial pro. l.es net of its exect. For both genders, it does not add signi..cantly to the model (likelihood ratio tests of model 5 vs. model 4 are 3.66 for men and 5.34 for women, with 4 d.f. and p-values of 0.45 and 0.25 respectively).

\section{TABLES 3, 4 AROUND HERE}

In Figure 3, we plotted the south-north pro. l.e of the log-odds-ratios for the hazard of .r.st sexual intercourse for males, derived from model 5, and in Figure 4 the same pro. l.e is shown for the west-east direction. Figures 5 and 6 represent spatial pro. l.es for females. For reference purposes, we indicated over the plots the location of some cities. As it appeared 
from the non-parametric analysis, the south-north gradient is evident and it is important for females. For both males and females, the peak of the risk of ..rst sexual intercourse is around the latitude corresponding (more or less) to the city of Rimini, with an odds-ratio of about 2.6 regarding the southernmost point. Much less variation is observed when the longitude pro. le is drawn.

\section{FIGURES 3, 4, 5 AND 6 AROUND HERE}

The advantage of the method we propose is that, by using spatial coordinates, we are able to draw maps using log-odds derived from the model. In Figures 7 and 8 we reproduced the maps of Italy from the model. The pictures we obtained are not far from the ones drawn, using non-parametric methods. The advantage here is that we used a full-information maximum likelihood approach, and parametric methods allow for more fexibility, e.g. control for timevarying covariates, also using standard existing packages which embed multilevel models. In our case, maps help to connect the results of the discretetime event history parametric model to those of the non-parametric approach. The south-north gradient for women, for instance, still clearly shows up, and for both sexes the peculiarities of the central-northern areas are visible.

\section{FIGURES 7 AND 8 AROUND HERE}

\section{Cohort dynamics}

We then focused our attention on societal change and split the data into two groups according to birth cohort. Given the size of the samples and the results of our past analysis (the low importance of space attributed to males), we performed this exercise for females only. The older cohort is composed of females born up to 1960, while the younger cohort consists of females born after 1961. We thus obtained groups that are almost balanced (46.6\% of the total female sample is in the older cohort). Cohort analysis is useful since it provides insight into the question whether behavior that is related to the ..r.st sexual intercourse is inłuenced by a spatial dixusion process. Following the same path we used 
before, wethen ..rst analyzed the spatial aspects of cohort dynamics, using non-parametric methods in the same fashion as shown in section 3. Then we considered parametric event history models in order to study the contribution of the spatial coordinates to the explanation of cohort changes 4. In the last subsection, we also used a more detailed de. nition of cohort, in that we allowed for cohort trends.

\subsection{Mapping cohort dynamics using nonparametric methods}

As was the case for the full sample, we .r.st performed an analysis based on the median survival computed aggregating data in provinces. We then carried out on an analysis based on the municipal frequency of 'early' ..rst intercourse.

The maps in Figure 9 show the geographic shape of the median survival age for the older and younger cohort. Cut points are chosen to be equal to the ones to which we referred to in the case of the whole sample. These maps are thus directly comparable with map (A) in Figure 1. The maps in Figure 10 show the geographic shape of the frequency with respect to the cut points used in the whole sample case. Thus these maps are directly comparable with map (A) in Figure 2.

\section{FIGURES 9 AND 10AROUND HERE}

Across the whole country, a general shift to early ..rst intercourse is visible. A remarkable stability is present in the south while in the center and in the north we observed a trend towards a behavior that is more homogeneous, which might be due to diausion

processes. This process appears to start from the two poles of the extreme north east and Emilia Romagna. A similar and fast development takes place in the island of Sardinia. The non-parametric analysis of cohort data thus provides evidence for a diausion exect.

\subsection{Parametric analysis of cohort dynamics}

In this part we limited our attention to the dixerential role of spatial coordinates in explaining variability at the time to ..rst sexual intercourse at the cohort level. The idea is that, if a spatial dixusion process underlies part of the observed dynamics, geographical 
coordinates should explain a larger share of the community-level variability (which also refects socio-economic and cultural factors).

We thus ..tted separate models, formulated as mode 4 in past analyses, for both cohorts. Results are presented in Table5. In theolder cohort, about half of the communitylevel estimated variance is explained when we introduce latitude and longitude splines. In the younger cohort, this share raises to more than $70 \%$. The results are consistent with those found when using the non-parametric method, and they provide some evidence that a spatial dixusion process is taking place.

To further investigate the role of spatial coordinates, we allowed the municipality-level variability to be continuously varying across birth cohorts, using a linear splineto represent the standard deviation as it varies across cohorts (we used year and month of birth, and knots are put every ..fth year). The results of this analysis are shown in Figure 11.

\section{FIGURE 11 AROUND HERE}

Similarly to table 5, we introduced geographical coordinates subsequently only. The ..gure shows a weak, but still interesting evidence of 1 ) the increasing role of municipalitylevel factors across cohorts, with 2) an increasing part of municipality-level factors which are explained merely by geographical coordinates.

TABLE 5 AROUND HERE

\section{Conclusions and discussion}

In this paper, we combined the techniques of event history analysis and spatial analysis jointly in order to analyze the age at .r.st sexual intercourse in I taly. By starting from FFS survey data linked to the geographical coordinates of the place of residence of respondents during their .r.st 15 years of life, we used non-parametric methods to draw maps capturing this phenomenon in Italy. Subsequently, we used discretetime event history models, including geographical coordinates as a municipality-level covariate. In our view, the simple use of geographical co-ordinates as area-level covariates, which is easily applicable 
to other studies with the use of standard software allowing for multilevel statistical models, is the major innovation of this paper. This approach also allows to build maps of relative odds of experiencing a certain event. Finally, we carried out an analysis of cohort dynamics, mainly in order to explorethe presence of spatial dixusion processes. Our proposals joining two important and so far rather separated streams of research, and we believe this is their main strength and novelty.

Concluding this paper, we would also like to stress the limitations of the proposed approach and of the analysis we were able to carry out. Given the limitations of our data, we did not fully exploit the possibilities of the proposed approach. In particular, individuals were attached to one municipality only, while the place of residence is clearly a timevarying covariate during the life course, especially if one looks at young adults. In general, we did not exploit the possibility of using timevarying covariates. Such opportunities should be exploited in future research exorts following the approach we propose.

From the technical side, the normality assumptions underlying the distribution of unobserved heterogeneity may be overcome by other, less stringent, assumptions. We followed a standard approach because we wanted to emphasize other aspects and we could not enter into the debate on assumptions concerning the distribution of unobserved characteristics. Another point, connected to the improved exploitation of geographical information systems, is the use of geographical coordinates. If micro-level data allow for that, ...ner references (eg. for large cities) can be used in future research, and this will allow for more precision in the de. nition of a decision-relevant context.

From the behavioural side, it is clear that this approach to analysis cannot be a means to an end. Explaining geographical variation is the next task. Maps and pro. l.e materials provide a subject for subsequent research, both on the theoretical and on the empirical side. For instance, a more re. ned analysis is necessary to further investigate the spatial dixusion of earlier .r.rst sexual intercourses in Italy. Our methods, however, allow us to analyze the dynamics of the role of space for behaviors for which event history analysis is an appropriate technique. 


\section{Disclaimer}

The views expressed in this paper are the authors' own and do not necessarily represent the views of the Max Planck Institute for Demographic Research.

\section{A cknowledgements}

Presentations based on former versions of this papers were given at the Conference of the Italian Coordinating Committe for Demography, Milan, February 2001, at the Workshop on Spatial Aspects of Demography, Rostock, Germany, May 2001, and at the Session S29 "Spatial Demographic Analysis", chaired by Danie Courgeau and J ean-Pierre BocquetAppe) at the XXIV IUSSP General Conference, Salvador, Brazil, August 2001. Wethank participants of the presentations for their useful comments. In particular, we are grateful to Arnstein Aassve, Susann Backer, Daniel Courgeau, and Gianpiero Dalla Zuanna for comments on earlier versions.

\section{R eferences}

Barber J .S., Murphy S.A., Axinn W.G., Maples J ., 2000, Discrete-Time Multilevel Hazard Analysis, Sociological Methodology, 30: 201-235.

Blossfeld H.-P., Rohwer G., 1995, Techniques of Event History Modeling. New Approaches to Causal Analysis. Lawrence Erlbaum Associates, Mahwah, NJ .

Bocquet-A ppe J .-P., Courgeau D., Pumain D. (Eds.), 1996, Spatial Analysis of Biodemographic Data. J ohn Libbey, Paris.

Bolstand W.M., Manda S.A., 2001, Investigating child Mortality in Malawi using family and community random exects: a bayesian analysis, J ournal of the American Statistical Association, 96, 12-19.

Bozon M., Kontula O., 1997, Initiation sexuelle et genre: comparaison des évolutions de douze pays européens, Population, 52, 1367-1400.

Buzzi C., 1998, Giovani, axettività, sessualità. L'amore tra i giovani in un'indagine IARD. il Mulino, Bologna. 
Cazzola A., 1999, L'ingresso nella sessualità adulta, in De Sandre P., Pinnelli A. e Santini A., Nuzialità e fecondità in trasformazione: percorsi efattori del cambiamento. il Mulino, Bologna.

Cleveland W.-S., 1979, Robust locally weighted regression and smoothing scatterplots, J ournal of the American Statistical Association, 74, 829-36.

Cleveland W.-S., Devlin S.-J ., 1988, Locally weighted regression: an approach to regression analysis by local ..tting J ournal of the American Statistical Association, 83, 596611.

Coale A.J ., Watkins S.C. (Eds.), 1986, The Decline of Fertility in Europe Princeton University Press, Princeton.

Congdon P., 2000, Monitoring Suicide Mortality: A Bayesian Approach, European J ournal of Population, 16: 251-284.

Courgeau D., Lelièvre É., 1989, Analyse démographique des biographies, Éditions de I'INED, Paris. English edition: 1992, Event history analysis in demography. Clarendon Press, Oxford.

Cressie N.A., 1993, Statistics for Spatial Data. Wiley, New York.

De Sandre P., Ongaro F., Rettaroli R., Salvini S., 1997, Matrimonio e ..gli: tra rinvio e rinuncia. il Mulino, Bologna.

Diggle P.J ., 1983, Statistical Analysis for Spatial Point Patterns. Academic Press, London.

DiggleP.J ., 2000, Overview of statistical methods for disease mapping and its relationship to cluster detection. In Spatial Epidemiology: methods and applications P. Elliott, J . C. Wake. .eld, N.G. Best, D. J . Brings (Eds.). Oxford University Press, Oxford.

Dunne M.P., Martin N.G., Statham D.J ., Pangan T., Madden P.A., Heath A.C., 1997, The consistency of recalled age at ..r.st sexual intercourse, J ournal of Biosocial Science, 29, 1-7.

ESRI, 1996, Using Avenue. Enviromental Systems Research Institute, Redlands, CA.

Fahrmeir L., Lang S., 2001, Bayesian inference for generalised additive mixed models based on random Markov ..eld priors. Applied Statistics, 50, 201-220.

Goldstein H., 1995, Multilevel Statistical Models, Second Edition. Edward Arnold, Lon- 
don.

Hastie T., Tibshirani R., 1990, Generalized Additive Models. Chapman and Hall, London.

Huber P.J . 1967, TheBehavior of Maximum Likelihood Estimates under Non-Standard Conditions. In: Proceedings of the F ifth Berkeley Symposium on Mathematical Statistics and Probability. University of California Press, Berkeley, CA: Vol. 1, 221-233.

Lesthaeghe R., Neds K., 2000, Maps, narratives and demographic innovation. IPDWP 2000-8, Interface Demography, Brussels.

Lillard L.A., Panis C.W.A., 2000, aML Multilevel Multiprocess Statistical Software, Release 1.0. EconWare, Los Angeles, CA.

Ripley B.D., 1981, Spatial Statistics. Wiley, New York.

Ripley B.D., 1988, Statistical Inference for Spatial Processes. Cambridge University Press, Cambridge.

Sleegers W.F., Goethals A.L.J ., 1993, Quantitative Geographical Methods. SISWO publication 366.

Steele F., Diamond I., Amin S., 1996, Immunization Uptake in Rural Bangladesh: a Multivel Analysis. J ournal of the Royal Statistical Society, 159: 289-299.

Venables W.N., Ripley B.D., 1999, Modern Applied Statistics with S-plus (3rd ed.). Springer, New York. 


\section{TABLES AND FIGURES}




\begin{tabular}{lllll}
\hline Parameters & \multicolumn{2}{c}{ Model } & \multicolumn{2}{c}{ Modd2 } \\
& estimate & std.error & estimate & std.error \\
\hline Constant & $-2.6629^{* *}$ & 0.0833 & $-2.6968^{* *}$ & 0.0883 \\
Age (reference=14-15) & & & & \\
$16-17$ & $1.1732^{* *}$ & 0.1098 & $1.1865^{* *}$ & 0.1098 \\
$18-19$ & $1.7941^{* *}$ & 0.1009 & $1.8350^{* *}$ & 0.1010 \\
$20-21$ & $1.6703^{* *}$ & 0.1128 & $1.7343^{* *}$ & 0.1140 \\
$22-23$ & $1.2941^{* *}$ & 0.1847 & $1.3766^{* *}$ & 0.1850 \\
$24-25$ & $1.5239^{* *}$ & 0.2166 & $1.6289^{* *}$ & 0.2243 \\
$26-$ & $0.3369 * *$ & 0.2101 & $0.4667^{*}$ & 0.2208 \\
& & & & \\
3/4 & & & $0.2352^{*}$ & 0.0945 \\
\hline log-likelihood & -2668.54 & & -2667.53 \\
\hline **: p-value<0.01, *: p-value<0.05
\end{tabular}

Table 1: Discrete time event history models 1-2. Males

\begin{tabular}{lllll}
\hline Parameters & \multicolumn{2}{c}{ Model1 } & \multicolumn{2}{c}{ Model2 } \\
& estimate & std. error & estimate & std. error \\
\hline Constant & $-3.8504^{* *}$ & 0.0723 & $-3.9125^{* *}$ & 0.0738 \\
Age (reference=14-15) & & & & \\
$16-17$ & $1.4922^{* *}$ & 0.0824 & $1.5182^{* *}$ & 0.0828 \\
$18-19$ & $2.3740^{* *}$ & 0.0795 & $2.4604^{* *}$ & 0.0793 \\
$20-21$ & $2.5083^{* *}$ & 0.0835 & $2.6617^{* *}$ & 0.0840 \\
$22-23$ & $2.3823^{* *}$ & 0.0882 & $2.5993^{* *}$ & 0.0877 \\
$24-25$ & $2.5518^{* *}$ & 0.0950 & $2.8119^{* *}$ & 0.0972 \\
$26-$ & $1.7543^{* *}$ & 0.0898 & $2.0995^{* *}$ & 0.0910 \\
& & & & \\
$3 / 4$ & & & $0.4056^{* *}$ & 0.0200 \\
\hline log-likelihood & -11453.41 & & -11359.30 \\
\hline **: p-value<0.01 & & & & \\
\hline
\end{tabular}

Table 2: Discrete time event history models 1-2. Females. 


\begin{tabular}{|c|c|c|c|c|c|c|}
\hline \multirow[t]{2}{*}{ Parameters } & \multicolumn{2}{|c|}{ Model3 } & \multicolumn{2}{|c|}{ Model4 } & \multicolumn{2}{|c|}{ Model5 } \\
\hline & estimate & std. error & estimate & std. error & estimate & std.error \\
\hline Constant & $-2.7370 * *$ & 0.3527 & $-1.7202^{* *}$ & 0.5008 & $-1.6800^{* *}$ & 0.5331 \\
\hline \multicolumn{7}{|c|}{ Age (reference=14-15) } \\
\hline $16-17$ & $1.1855 * *$ & 0.1116 & 1.1804** & 0.1118 & 1.1828** & 0.1127 \\
\hline $18-19$ & $1.8324^{* *}$ & 0.1016 & $1.8239 * *$ & 0.1030 & $1.8270^{* *}$ & 0.1042 \\
\hline $20-21$ & $1.7304 * *$ & 0.1144 & $1.7204 * *$ & 0.1144 & $1.7211^{* *}$ & 0.1158 \\
\hline $22-23$ & $1.3725^{* *}$ & 0.1906 & $1.3503^{* *}$ & 0.1922 & $1.3497 * *$ & 0.1976 \\
\hline $24-25$ & $1.6261^{* *}$ & 0.2222 & $1.5971 * *$ & 0.2206 & $1.6106 * *$ & 0.2340 \\
\hline $26-$ & $0.4614^{*}$ & 0.2314 & $0.4255+$ & 0.2191 & $0.4471^{*}$ & 0.2228 \\
\hline \multicolumn{7}{|c|}{ Latitude spline (origin= $36^{ \pm} 389 \mathrm{~N}$ ) } \\
\hline Slope-38 & 0.0736 & 0.3271 & 0.0212 & 0.3175 & -0.0556 & 0.3291 \\
\hline Slope 38-39 & $-0.6554 *$ & 0.3215 & $-0.8804 *$ & 0.3547 & $-0.8914 *$ & 0.3587 \\
\hline Slope 39-40 & 0.5116 & 0.3315 & $0.7477+$ & 0.4357 & $0.7980+$ & 0.4552 \\
\hline Slope 40-41 & 0.1837 & 0.2488 & 0.1329 & 0.3849 & 0.1165 & 0.4025 \\
\hline Slope 41-42 & 0.0019 & 0.2360 & -0.0320 & 0.2841 & -0.1412 & 0.2899 \\
\hline Slope 42-43 & 0.0088 & 0.3102 & -0.0265 & 0.3294 & 0.1369 & 0.3390 \\
\hline Slope 43-44 & 0.2375 & 0.3072 & 0.1790 & 0.3009 & 0.1640 & 0.3035 \\
\hline Slope 44-45 & $-0.5030 *$ & 0.2265 & $-0.6287^{*}$ & 0.2476 & $-0.6651^{* *}$ & 0.2516 \\
\hline Slope 45- & 0.1218 & 0.1801 & 0.2704 & 0.2013 & 0.2722 & 0.1979 \\
\hline \multicolumn{7}{|c|}{ Longitude spline (origin=6士379E ) } \\
\hline Slope -9 & & & $-0.3275^{*}$ & 0.1425 & $-0.3195^{*}$ & 0.1503 \\
\hline Slope 9-11 & & & 0.0016 & 0.0868 & -0.0228 & 0.0926 \\
\hline Slope 11-13 & & & -0.0322 & 0.1172 & -0.0039 & 0.1179 \\
\hline Slope 13-15 & & & -0.0970 & 0.1371 & -0.1030 & 0.1356 \\
\hline Slope 15-17 & & & 0.1593 & 0.1471 & 0.1849 & 0.1490 \\
\hline Slope 17- & & & -0.2839 & 0.3057 & -0.3377 & 0.3140 \\
\hline \multicolumn{7}{|c|}{ Population spline (origin=0) } \\
\hline $0-5,000$ & & & & & 0.0251 & 0.0373 \\
\hline $5,000-20,000$ & & & & & -0.0138 & 0.0094 \\
\hline $20,000-100,000$ & & & & & 0.0009 & 0.0018 \\
\hline $100,000-1,000,000$ & & & & & 0.0001 & 0.0001 \\
\hline \multicolumn{7}{|l|}{$1,000,000$} \\
\hline $3 / 4$ & 0.1644 & 0.1122 & & & & \\
\hline log-likelihood & -2660.26 & & -2655.40 & & -2653.57 & \\
\hline
\end{tabular}

Table 3: Discrete time event history models 3-5. Males 


\begin{tabular}{|c|c|c|c|c|c|c|}
\hline \multirow[t]{2}{*}{ Parameters } & \multicolumn{2}{|c|}{ Model3 } & \multicolumn{2}{|c|}{ Model4 } & \multicolumn{2}{|c|}{ Model5 } \\
\hline & estimate & std. error & estimate & std. error & estimate & std. error \\
\hline Constant & $-4.4179 * *$ & 0.2815 & $-4.1571^{* *}$ & 0.3360 & $-4.1341 * *$ & 0.3476 \\
\hline \multicolumn{7}{|c|}{ Age ( reference $=14-15$ ) } \\
\hline $16-17$ & $1.5164 * *$ & 0.0835 & $1.5168 * *$ & 0.0835 & $1.5170 * *$ & 0.0869 \\
\hline 18-19 & $2.4687 * *$ & 0.0809 & $2.4698 * *$ & 0.0809 & $2.4706 * *$ & 0.0814 \\
\hline $20-21$ & $2.6777 * *$ & 0.0854 & $2.6792 * *$ & 0.0852 & $2.6801 * *$ & 0.0858 \\
\hline $22-23$ & $2.6254 * *$ & 0.0885 & $2.6278 * *$ & 0.0885 & $2.6290 * *$ & 0.0896 \\
\hline $24-25$ & $2.8475 * *$ & 0.1010 & $2.8484 * *$ & 0.1005 & $2.8489 * *$ & 0.0995 \\
\hline $26-$ & $2.1430^{* *}$ & 0.0940 & $2.1339 * *$ & 0.0928 & $2.1377 * *$ & 0.0930 \\
\hline \multicolumn{7}{|c|}{ Latitude spline (origin=36士389 ) } \\
\hline Slope -38 & -0.0305 & 0.2573 & -0.0328 & 0.2368 & 0.0272 & 0.2392 \\
\hline Slope 38-39 & 0.2351 & 0.2191 & 0.2835 & 0.2213 & 0.2555 & 0.2240 \\
\hline Slope 39-40 & -0.0574 & 0.2268 & -0.0016 & 0.2640 & -0.0073 & 0.2746 \\
\hline Slope 40-41 & -0.0864 & 0.1550 & -0.1737 & 0.1740 & -0.2072 & 0.1859 \\
\hline Slope 41-42 & $0.7996 * *$ & 0.1281 & $0.5790^{* * *}$ & 0.1762 & $0.5316 * *$ & 0.1929 \\
\hline Slope 42-43 & $-0.2921+$ & 0.1754 & -0.2784 & 0.1955 & -0.1820 & 0.2046 \\
\hline Slope 43-44 & $0.5586 * *$ & 0.1853 & $0.5471 * *$ & 0.1925 & 0.4948* & 0.1924 \\
\hline Slope $44-45$ & $-0.4394 * *$ & 0.1321 & $-0.2876 *$ & 0.1378 & -0.2430 & 0.1403 \\
\hline Slope 45- & 0.0675 & 0.0851 & -0.0080 & 0.0856 & -0.0038 & 0.0877 \\
\hline \multicolumn{7}{|c|}{ Longitude spline (origin $=6^{ \pm 379}$ E ) } \\
\hline Slope -9 & & & $-0.1515+$ & 0.0855 & $-0.2269 * *$ & 0.0850 \\
\hline Slope 9-11 & & & $0.1956 * *$ & 0.0485 & $0.2041 * *$ & 0.0504 \\
\hline Slope 11-13 & & & -0.0555 & 0.0581 & -0.0486 & 0.0599 \\
\hline Slope 13-15 & & & $-0.1406+$ & 0.0775 & $-0.1378+$ & 0.0800 \\
\hline Slope 15-17 & & & 0.0356 & 0.0815 & 0.0301 & 0.0869 \\
\hline Slope 17- & & & -0.0872 & 0.1778 & -0.0842 & 0.1816 \\
\hline \multicolumn{7}{|c|}{ Population spline (origi $\mathrm{n}=0$ ) } \\
\hline $0-5,000$ & & & & & 0.0153 & 0.0215 \\
\hline $5,000-20,000$ & & & & & 0.0001 & 0.0058 \\
\hline $20,000-100,000$ & & & & & 0.0011 & 0.0012 \\
\hline $100,000-1,000,000$ & & & & & 0.0000 & 0.0001 \\
\hline \multicolumn{7}{|l|}{$1,000,000$} \\
\hline $3 / 4$ & $0.2909 * *$ & 0.0254 & $0.2647 * *$ & 0.0270 & $0.2682^{* *}$ & 0.0297 \\
\hline log-likelihood & -11257.55 & & -11246.87 & & -11244.20 & \\
\hline
\end{tabular}

Table 4: Discrete time event history models 3-5. Females. 


\begin{tabular}{|c|c|c|c|c|c|}
\hline \multirow[b]{2}{*}{ Cohorts } & \multicolumn{2}{|c|}{\begin{tabular}{l}
\multicolumn{1}{c}{ a } \\
Model without \\
coordinates
\end{tabular}} & \multicolumn{2}{|c|}{$\begin{array}{c}\mathrm{b} \\
\text { Model with } \\
\text { coordinates }\end{array}$} & \multirow[t]{2}{*}{$\begin{array}{l}c=1 \mathrm{i}\left(\mathrm{a}^{2} \mathrm{i} \mathrm{b}^{2}\right)=\mathrm{a}^{2} \\
\text { Variance }(\%) \text { explained by } \\
\text { geographical coordinates }\end{array}$} \\
\hline & estimate & std.error & estimate & std.error & \\
\hline $\begin{array}{l}1946-1960 \\
3 / 4\end{array}$ & $0.3162^{* *}$ & 0.0370 & $0.2233^{* *}$ & 0.0527 & $50.1 \%$ \\
\hline $\begin{array}{l}1961-1975 \\
3 / 4\end{array}$ & $0.4801 * *$ & 0.03865 & $0.2503 * *$ & 0.0501 & $72.8 \%$ \\
\hline
\end{tabular}

Table 5: Discrete time event history models 1-2. Males

Figure 1: Median age at ..rst intercourse: (A) females (B) males

\section{(A)}

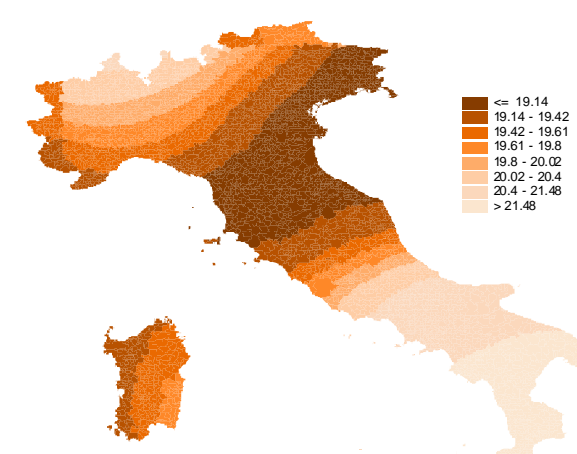

(B)

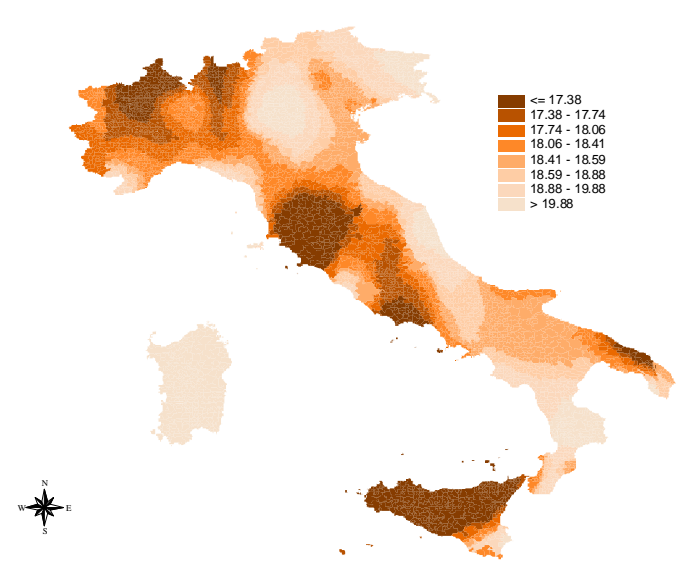


Figure 2: Frequency of 'early' ..rst intercourse: (A) females (B) males

(A)

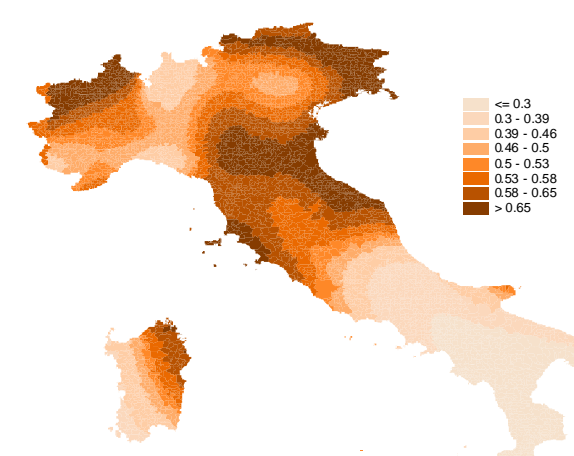

(B)

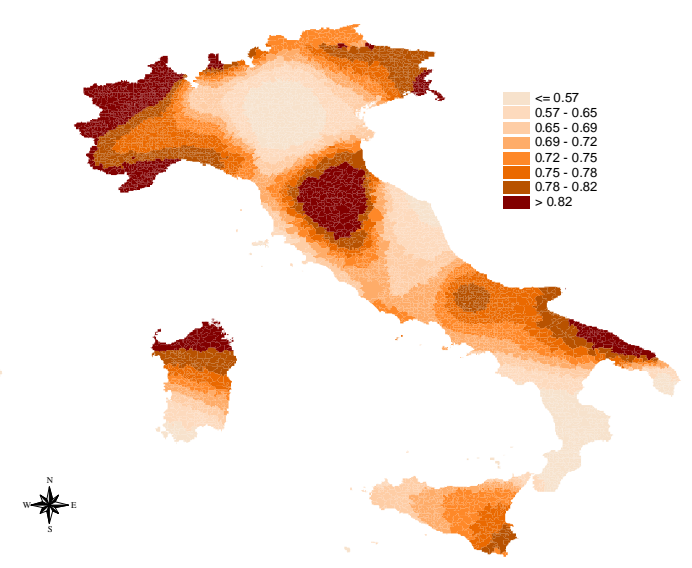

Figure 3: Spatial pro. l.e by latitude: Males

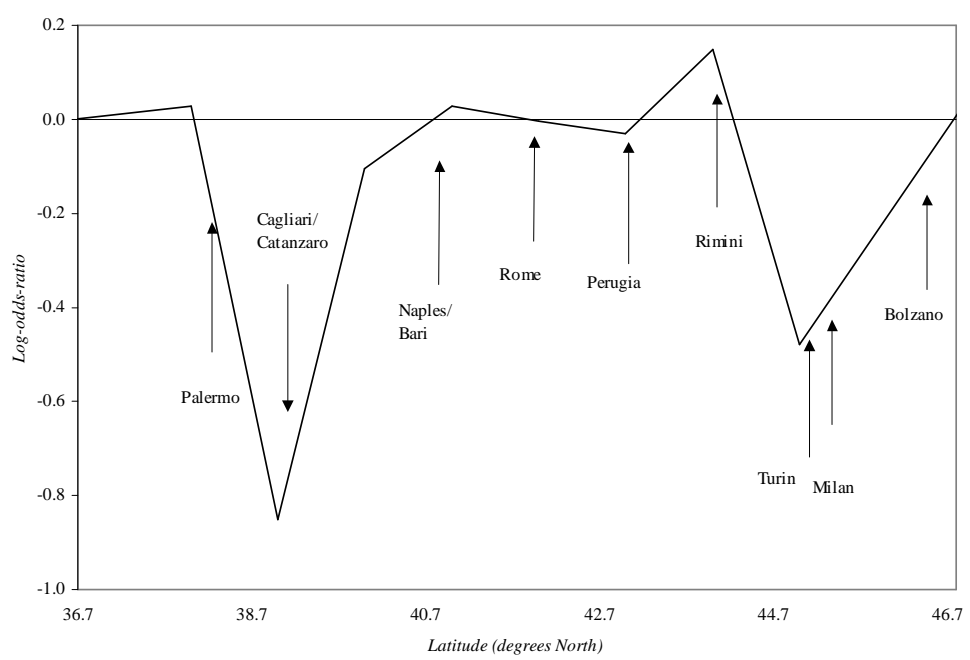


Figure 4: Spatial pro. I.e by longitude: Males

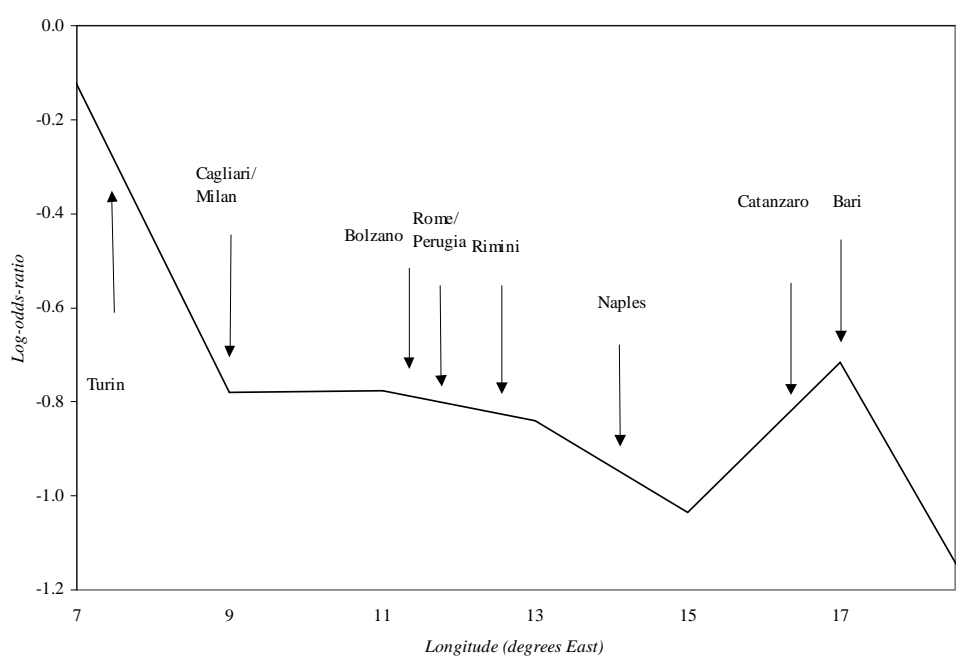

Figure 5: Spatial pro. les by latitude: Females

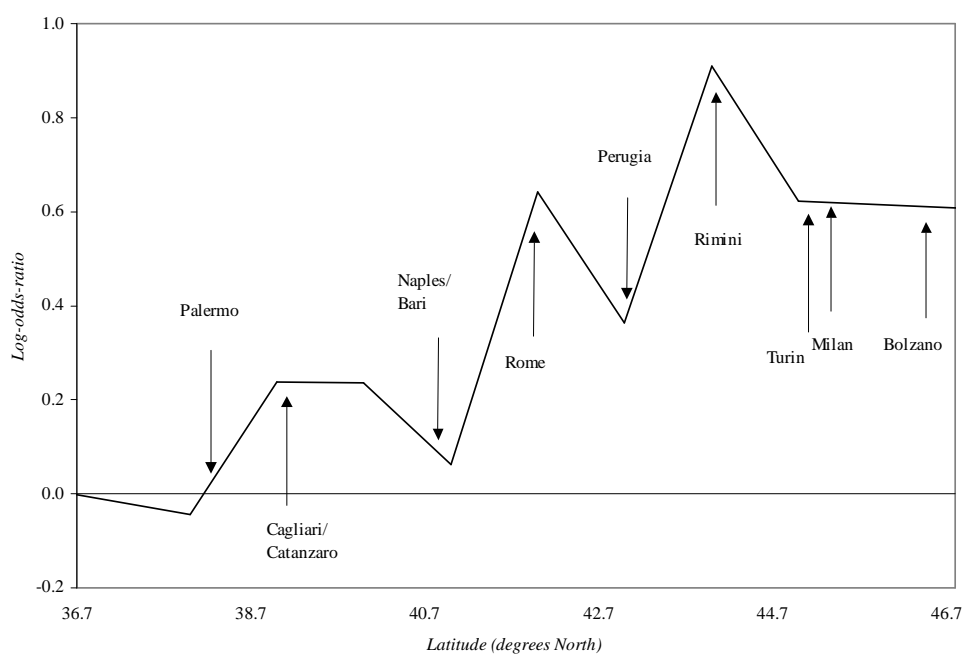


Figure 6: Spatial pro. l.es by longitude: Females

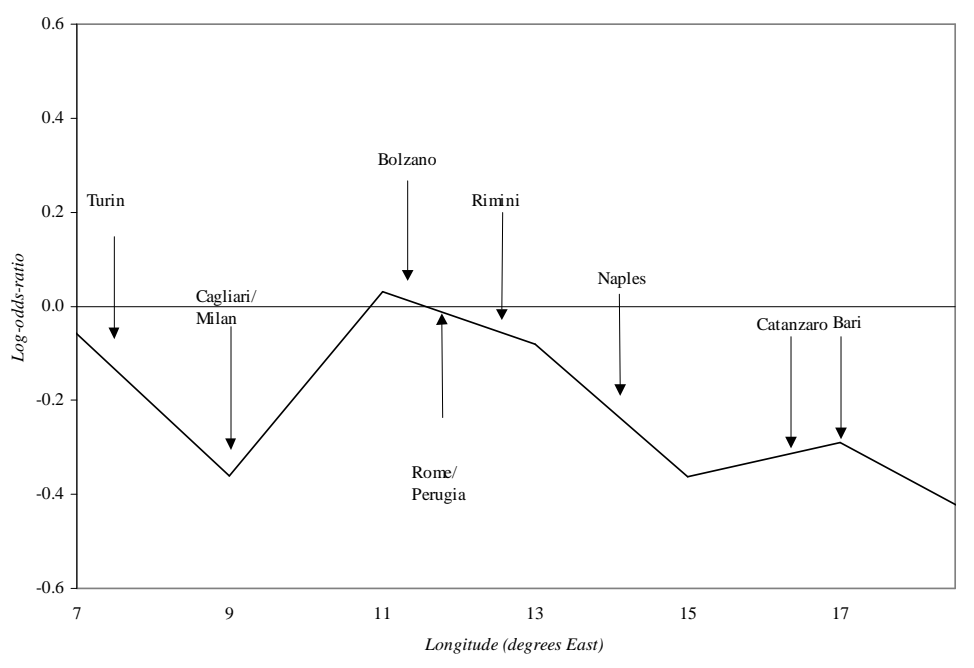

Figure 7: Map of log odds: Females

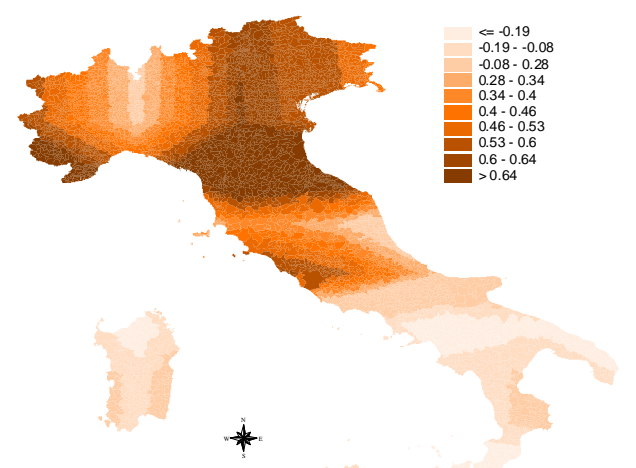


Figure 8: Map of log odds: Males

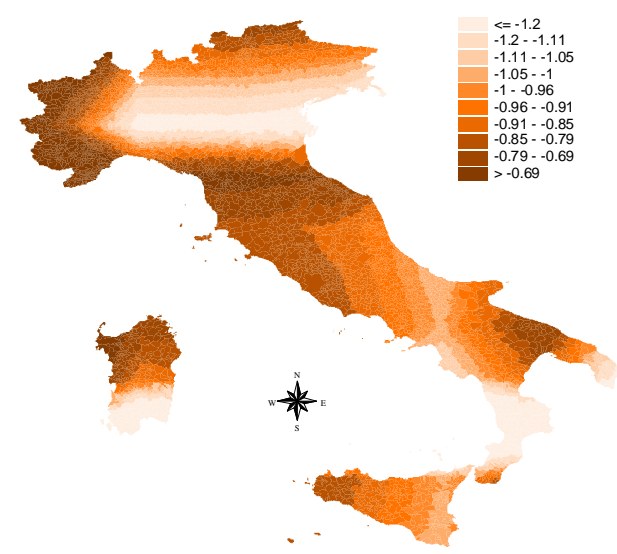


Figure 9: Maps of median age at ..rst intercourse for older (A) and younger (B) cohort: Females

(A)

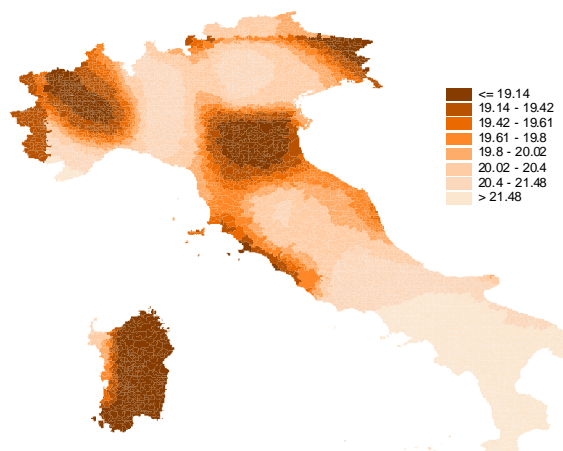

(B)

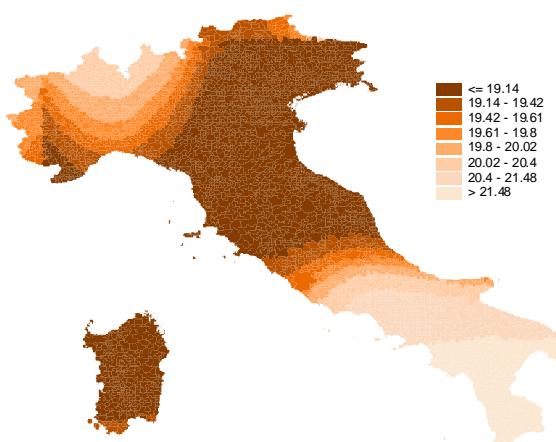

* 
Figure 10: Maps of 'early' ..rst intercourse: Older (A) and younger (B) cohort: Females

(A)

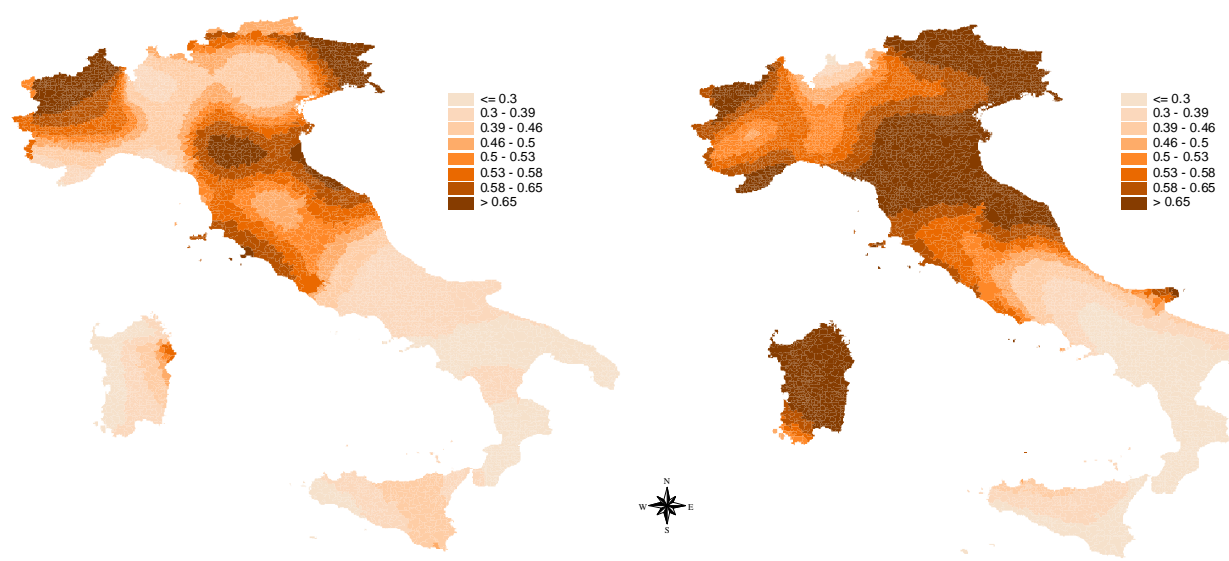

Figure 11: Standard deviation by cohort (linear spline)

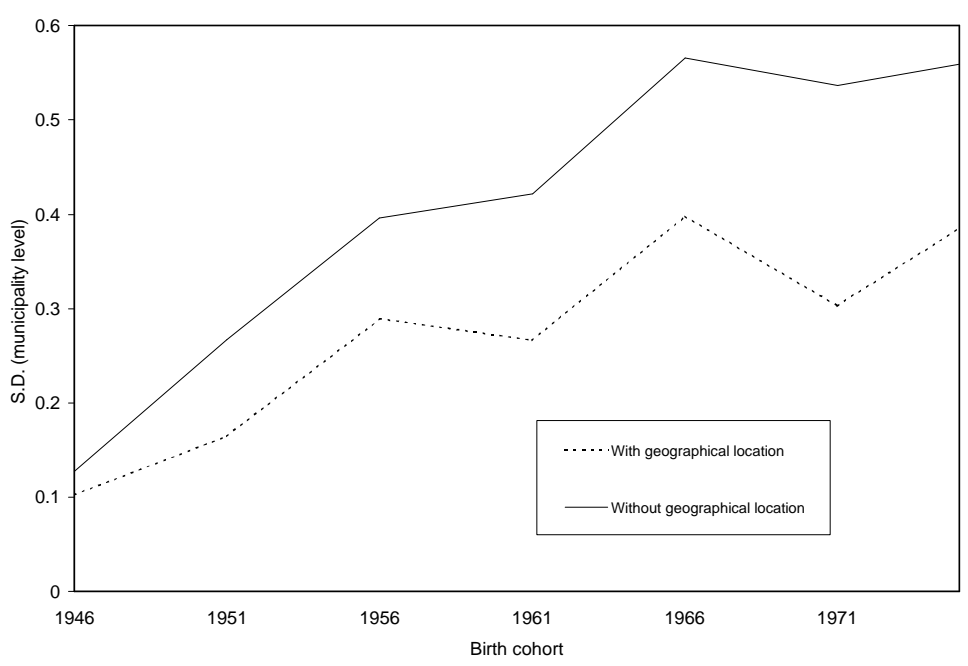

